\title{
The inside out mirror
}

\author{
Sue Pearson ${ }^{1}$
}

Received: 30 September 2020 / Accepted: 5 October 2020 / Published online: 24 October 2020

(c) Springer-Verlag London Ltd., part of Springer Nature 2020

The automated algorithms in artificial intelligence are reflections of the brain's own algorithms, so that the online world can act as a mirror to reveal previously hidden internal workings of the brain that have impacted society for millennia. This inside-out mirror offers the possibility of transforming society itself.

The earliest part of the brain to develop in a baby is the reptilian core in the Primal Brain at the base of the skull, inherited from the age of predatory cold-blooded reptiles. It is connected to the unconscious, the underground energy store of unused, rejected or overused human potential that in some people can be twisted into negative thinking and behaviour. Like computers, the reptilian core uses binary algorithms to run internal automated systems, including survival responses to threats, and to create the foundations of the brain's mental constructs that process information and predict future events (Pearson 2015). However, if these simplistic binary categories of black or white, kill or die, 'me' or 'them' are not later updated by complex information from more evolved parts of the brain, they can cause difficulties for the individual and divisions between social groups. AI, the internet and social media's use of binary algorithms can over-stimulate the automated algorithms in the reptilian cores of their users, releasing extremist or nationalistic 'us' or 'them' thinking, and twisted fake news, hatred, misogyny and abuse from their unconscious.

In the "Age of Surveillance Capitalism", Shoshana Zuboff (2019) exposes the misappropriation of internet users' surplus data to modify and manipulate their behaviour for the benefit of third parties. If we turn the mirror of the internet inwards, we see that this hidden extraction of 'waste data' is not unprecedented. The unconscious has always taken unused human potential to later modify, manipulate and take control of behaviour in mental illness, violence or psychopathy.

\section{Sue Pearson}

globalmidlifecrisis@gmail.com

1 Apple Court, South St, Totnes TQ9 5DZ, UK
Twisting the relative importance between artificial automated algorithms and human intelligence reflects the twisted thinking of the unconscious; for example Steve Fuller in AI and Society (2019) said that "the brain should be seen as a biologically based form of AI" (my emphasis). This contortion is a twisted thread that runs through thinking about AI's future role in society, but it also coils back to the failure by the reptilian core in some early humans to adapt to changing circumstances.

Early groups of hunters and gatherers were egalitarian (Boehm 1999). That changed when gatherers, using their knowledge of plants and caring for the young, began growing crops, enclosing land and animals to build communities in the Agricultural Age (Scott 2017). It was the beginning of civilisation. This evolutionary leap forward reflected the advance from Primal Brain survival to the development of the more advanced, society-creating part of the brain. However, once animals were farmed and meat more easily available, hunters, with their well-developed, predatory reptilian cores, became largely redundant. Most adapted but others failed to progress, and instead regressed to the hierarchical and violent behaviour of our primate ancestry. Angry at their loss of status, pathological hunters turned their cold-blooded cunning and killing skills onto their own kind to become violent leaders backed by a warrior elite, taking the produce of others to consolidate their power (Livingstone Smith 2011). It is a strategy used by dictators throughout history, and some political leaders still promise to make those left behind by social changes and the loss of their status-giving jobs feel great again, driven by the belief of "Be a killer, be a king" (Wolff 2018).

The dominance of the prehistoric reptilian core twisted values in the earliest societies, so that 'things' like money, power and possessions became more important than people. It led to war, racism, elitism, poverty and slavery. Today man the hunter continues to prowl the urban jungle in search of prey, still lives on in the sexual predator who brings his victim down; or he 'makes a killing' on the stock market, and raises his head in the fat cats who live off the work of others. This split between the reptilian core's automated algorithms 
and the more advanced society-creating part of the brain continues to this day: the hunter preys on the young, the weak and the old, the same groups that a civilised society cares for and seeks to protect.

The early takeover by the reptilian core was recorded in the myth of the deceitful, manipulative and greedy 'Serpent' that has continued to undermine human development over the millennia. And now the myth from religion is made reality. "In the world of lies, humans are led to believe they cannot rely on anything else to survive; that love is a thought and has no object reality; that humans are motivated primarily by money; that to compete for money is the only intelligent way to live. This world can use any human weaknessgreed or pride—or any tactic, to gain control, but it must use humans to do its work. This world is intangible and immaterial but it is real." These words by Scott Peck (1983) about the Serpent's world could apply to surveillance capitalism, media manipulation and online abuse today. The same field of knowledge that created the Serpent myth also offered a new model to replace Man the Hunter 2000 years ago: that of Man the Shepherd. Perhaps it is due for a revival?

By turning the AI and internet mirror inwards, we have the insight to put the reptilian core in its place as a necessary survival part of the brain, but which has to be subservient to the thinking and decision-making of more evolved brain functions. As we seek to free ourselves from manipulation by tech companies, can we also free ourselves from our own automated algorithms and transform our external and internal worlds? This would ensure people come before automated algorithms, and society comes before AI. But first we need to understand better how the brain and unconscious work.

\section{References}

Boehm C (1999) Hierarchy in the forest. Harvard University Press, Cambridge

Fuller S (2019) AI Soc 34(4):825-833

Livingstone Smith D (2011) Less than human. St Martin's Griffin, New York

Pearson S (2015) Integrated thinking: the new IT. KDP Amazon Seattle USA

Scott J (2017) Against the grain. Yale University Press, New Haven

Scott Peck M (1983) People of the lie. Simon \& Schuster, London

Wolff M (2018) Fire and fury. Little, Brown, London

Zuboff S (2019) The age of surveillance capitalism. Profile Books, London

Publisher's Note Springer Nature remains neutral with regard to jurisdictional claims in published maps and institutional affiliations. 